\title{
Road traffic accidents in Bangladesh: A top public health issue?
}

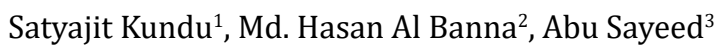

\section{AFFILIATION}

1 Department of Biochemistry and Food Analysis, Patuakhali Science and Technology University, Patuakhali, Bangladesh

2 Department of Food Microbiology, Patuakhali Science and Technology University, Patuakhali, Bangladesh

3 Department of Post-Harvest Technology and Marketing, Patuakhali

Science and Technology University, Patuakhali, Bangladesh

CORRESPONDENCE TO

Satyajit Kundu. Department of Biochemistry and Food Analysis, Patuakhali Science and Technology University, Patuakhali, 8602,

Popul. Med. 2020;2(May):11
Bangladesh. E-mail: satyajitnfs@gmail.com ORCID ID: https://orcid. org/0000-0001-9610-1479

KEYWORDS

road traffic accidents, public health, Bangladesh

Received: 9 April 2020, Revised: 22 April 2020, Accepted: 22 April 2020

\section{Dear Editor,}

Road traffic accidents (RTAs) are the leading cause of injuryrelated deaths globally. The road safety crisis has become a global epidemic comparable to diseases such as malaria, tuberculosis or HIV. About 1.35 million people globally die every year in road accidents, and more than one-fourth of these fatalities are estimated to happen in South Asia ${ }^{1}$. The World Health Organization (WHO) and the World Bank have noted that, by 2020, deaths from RTAs would become a main cause of mortality in many countries ${ }^{2}$.

There has been an alarming rise in road traffic accidents in Bangladesh over the past few years, which has become a national problem. Every day about eight people die in RTAs, but the actual rate of fatality is likely to be higher ${ }^{3}$. In 2019, at least 5227 people were killed and 6953 injured in 4702 road accidents across the country ${ }^{4}$, with accompanying increased healthcare costs for Bangladesh. Moreover, there is a shortage of traffic laws in Bangladesh, which has the lowest traffic law compliance rate compared to other countries in South Asia ${ }^{5}$. Bangladesh loses 1.2 billion pounds per year due to RTAs, which is equivalent to $2 \%$ of GDP and all of the foreign aid it receives annually ${ }^{6}$. Over $70 \%$ of poor households report that their household income and food consumption decreased and $61 \%$ were forced to arrange a loan after a road death in Bangladesh ${ }^{7}$. RTAs in Bangladesh have yet to get proper attention, which is alarming and the time has arrived to confront this challenge.

A common factor to reduce RTAs is the collection and use of comprehensive data. The interpretation of these data can lead to a better understanding of operational problems, accurate diagnosis of accident problems, and https://doi.org/10.18332/popmed/120968 the development of remedial measures. However, there is a lack of adequate research on RTAs in Bangladesh and more research is needed to identify the actual causes and ways to reduce RTAs.

\section{REFERENCES}

1. The World Bank. World Bank \& UN Join Hands with Bangladesh to Improve Road Safety. https://www.worldbank. org/en/news/press-release/2019/09/24/world-bankun-join-hands-with-bangladesh-to-improve-road-safety. Published 2019. Accessed April 22, 2020.

2. World Health Organization. The Global Burden of Disease: 2004 Update. Geneva, Switzerland: World Health Organization; 2008. https://www.who.int/healthinfo/global_ burden_disease/2004_report_update/en/. Accessed 22 April, 2020.

3. Standard Transport Planning. Urban Transport Policy: The Strategic Transport Plan (STP) for Dhaka. Dhaka, Bangladesh: Dhaka Transport Coordination Board (DTCB); 2005.

4. The Daily Star. Road Accident: 5,227 killed in 2019. https:// www.thedailystar.net/country/bangladesh-road-accidentsin-2019-saw-significant-rise-1849381. Published 2020. Accessed April 9, 2020.

5. World Health Organization. Road safety in the SouthEast Asia Region 2015. Geneva, Switzerland: World Health Organization; 2015. https://apps.who.int/iris/ handle/10665/249151. Accessed April 9, 2020.

6. Alam AB. Road Traffic Accidents in Bangladesh. J Bangladesh Coll Physicians Surg. 2018;36(4):137-138. doi:10.3329/jbcps.v36i4.38178

7. Quazi M, Engineer ST. Road Safety and Povery Dynamics in 
Bangladesh. In: International Conference on Road Safety in Developing Countries, 22-24 August. Dhaka, Bangladesh: Accident Research Centre (ARC), Bangladesh University of Engineering \& Technology (BUET); 2006. 